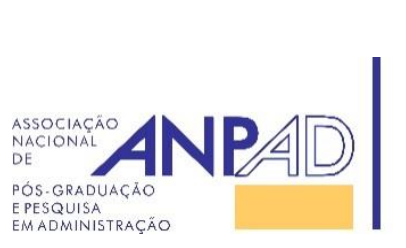
Disponível em
http://www.anpad.org.br/rac
RAC, Rio de Janeiro, v. 20, n. 1, art. 4, pp. 64-83, Jan./Fev. 2016
(c) EY

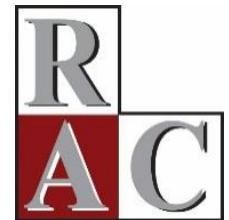

\title{
Desaprendizagem Organizacional: Um Estudo de Campo na Universidade Federal de Santa Catarina
}

Organizational Unlearning: An Empirical Study in the Federal University of Santa Catarina

Gustavo Tomaz Buchele ${ }^{1}$ Pierry Teza ${ }^{1}$

Isabela Regina Fornari Müller ${ }^{1}$ João Artur de Souza ${ }^{1}$

Universidade Federal de Santa Catarina ${ }^{1}$ 


\title{
Resumo
}

Ao mesmo tempo em que as organizações adquirem novos conhecimentos, processo este chamado de aprendizagem organizacional, elas também descartam os obsoletos, processo denominado desaprendizagem organizacional. Desaprendizagem organizacional se refere ao descarte de velhas rotinas para abrir caminho para novas, e seu estudo tem recebido limitada atenção das pesquisas. Assim, a partir da necessidade de maior entendimento de como ocorre o processo de desaprendizagem, o estudo aqui apresentado objetivou descrever o processo de desaprendizagem organizacional em um setor de uma organização pública, contexto ainda menos estudado, se comparado com organizações privadas. Para isso, utilizando como suporte a teoria de rotinas organizacionais, utilizou-se da pesquisa de campo para descrever o processo de desaprendizagem organizacional em uma das Pró-Reitorias da Universidade Federal de Santa Catarina. Verificou-se, entre outros pontos, que as mudanças funcionam como alavancas para a desaprendizagem organizacional, e que aprendizagem e desaprendizagem organizacional estão intimamente ligadas por meio da incorporação e descarte de rotinas organizacionais.

Palavras-chave: conhecimento; desaprendizagem organizacional; mudança.

\begin{abstract}
While organizations acquire new knowledge, a process called organizational learning, they also discard obsolete knowledge, a process called organizational unlearning. Organizational unlearning focuses on the disposal of old routines to make way for new ones, and its study has received limited attention from research. Thus, due to the need for greater understanding of the unlearning process, the study presented here aims to describe the organizational unlearning process in a public organization, a context even less studied than private organizations. For this, support by the theory of organizational routines, we used field research to describe the organizational unlearning process in one of Colleges of the Federal University of Santa Catarina. Among other things, changes were found to act as levers for organizational unlearning, and organizational learning and unlearning are closely linked through the introduction and disposal of organizational routines.
\end{abstract}

Key words: knowledge; organizational unlearning; change. 


\section{Introdução}

No atual ambiente de negócios, rápidas mudanças e eventos imprevisíveis ocorrem continuamente (Akgün, Byrne, Lynn, \& Keskin, 2007). As mudanças são, em parte, o resultado do crescimento do mercado ou desenvolvimento de tecnologias, e elas criam turbulências que podem destruir as competências existentes em uma organização (Tushman \& Anderson, 1986). Além disso, crenças e métodos têm sido amplamente aceitos e estabelecidos pelas organizações, fazendo com que elas negligenciem novas tecnologias e mercados pelo fato de elas terem grande investimento emocional em velhas formas de trabalho (Akgün et al., 2007). Com isso, parte do conhecimento existente acaba se tornando obsoleto e, caso uma organização persista na utilização desse conhecimento, pode, entre outros malefícios, resultar na perda de tempo e recursos (Akgün et al., 2007; Tsang \& Zahra, 2008). Nesse sentido, a incapacidade de desaprender torna-se uma fraqueza crítica de muitas organizações (Hedberg, 1981).

Dado o exposto, percebe-se que muitos dos conhecimentos adquiridos se tornam obsoletos, fazendo com que seja necessária a aquisição de novos conhecimentos de maneira contínua, uma vez que, tornando-se obsoleto, o conhecimento deve ser renovado (Hedberg, 1981). Dessa forma, ao mesmo tempo em que as organizações adquirirem novos conhecimentos, também descartam os obsoletos. $\mathrm{O}$ primeiro processo chama-se aprendizagem organizacional e o segundo, desaprendizagem organizacional. $\mathrm{O}$ processo de desaprendizagem organizacional é considerado como o descarte intencional de rotinas, sendo um importante elemento tanto para a adaptação às mudanças do ambiente quanto para a promoção da aprendizagem organizacional e manutenção da competitividade (Tsang \& Zahra, 2008).

Apesar de o tema aprendizagem organizacional ter avançado nas pesquisas, a questão da desaprendizagem organizacional tem recebido limitada atenção (Akgün et al., 2007; Srithika \& Bhattacharyya, 2009; Tsang \& Zahra, 2008). Essa atenção é ainda mais limitada quando se trata de organizações públicas. Assim, a partir da necessidade de melhor entendimento da desaprendizagem organizacional no contexto de organizações públicas, o estudo aqui apresentado objetivou descrever como ocorre esse processo em uma das Pró-Reitorias da Universidade Federal de Santa Catarina.

O presente trabalho está estruturado em cinco seções. A primeira e presente seção corresponde à introdução do trabalho. A segunda lança os fundamentos teóricos utilizados como base para o estudo. Na terceira seção são explicitados os aspectos metodológicos. Na quarta seção são apresentados e discutidos os resultados do estudo. Finalmente, na quinta seção são realizadas as considerações finais, bem como explicitados pontos que poderão ser abordados por futuros trabalhos e as limitações do estudo.

\section{Fundamentação Teórica}

Serão tratados no referencial teórico temas que serviram de base para a realização da pesquisa, sendo eles: desaprendizagem organizacional, rotinas organizacionais, memória organizacional, aprendizagem organizacional e mudança organizacional.

\section{Desaprendizagem organizacional}

A dificuldade em compreender como as organizações podem desaprender vem do fato de que os pesquisadores têm dedicado pouco esforço para articular o domínio do conceito (Tsang \& Zahra, 2008). Um melhor entendimento do tema pode ser alcançado pela discussão de dois termos encontrados na literatura: desaprendizagem e esquecimento organizacional. Martin de Holan e Phillips (2004) definem esquecimento organizacional como "a perda, voluntária ou não, do conhecimento organizacional" (p. 1606). Os autores ainda consideram que desaprendizagem é um tipo de esquecimento, que ocorre 
quando o conhecimento organizacional é propositadamente removido (Martin de Holan \& Phillips, 2004).

Easterby-Smith e Lyles (2011) diferenciam desaprendizagem organizacional de esquecimento organizacional afirmando que ambas tratam de perda de conhecimento, porém a desaprendizagem se refere à tentativa deliberada de eliminar conhecimento indesejado, ao passo que esquecimento diz respeito a uma perda de conhecimento que não é necessariamente planejada ou pretendida. Dessa forma, considera-se que o esquecimento organizacional é a perda inadvertida de rotinas organizacionais (Tsang \& Zahra, 2008).

Tsang e Zahra (2008), a partir da visão orientada a rotinas, afirmam que desaprendizagem organizacional se refere ao "descarte de velhas rotinas para abrir caminho para novas, se houver" (p. 1437). Os autores complementam que desaprendizagem é um processo intencional, que não pressupõe juízo de valor sobre o que é descartado e também não presume a inserção de novas rotinas no lugar do que foi descartado, o que envolveria mudanças cognitivas e comportamentais (Tsang \& Zahra, 2008). Diante disso, neste estudo foi utilizada a visão de desaprendizagem organizacional como ação deliberada e baseada no descarte de rotinas, apresentada por Tsang e Zahra (2008).

\section{Rotinas organizacionais}

As rotinas organizacionais são consideradas uma característica central das organizações humanas e um mecanismo que explica muitas das teorias mais aceitas, podendo ser definidas como "um padrão repetitivo e identificável de ações interdependentes envolvendo múltiplos atores" (Feldman \& Pentland, 2003, p. 96). O conceito de rotinas foi introduzido por Stene (1940) e tem sido considerado como o principal meio pelo qual as organizações realizam suas atividades (Nelson \& Winter, 1982).

De acordo com Feldman e Pentland (2003), é possível extrair três metáforas de rotinas organizacionais que, juntas, criam uma história relativamente coerente sobre a natureza das rotinas organizacionais, suas causas e suas consequências, conforme Tabela 1.

Tabela 1

\section{Metáforas sobre Rotinas Organizacionais}

\begin{tabular}{|c|c|}
\hline Metáforas & Descrição \\
\hline Rotinas como hábitos individuais & $\begin{array}{l}\text { A primeira metáfora compara as rotinas organizacionais com os } \\
\text { hábitos individuais (Nelson \& Winter, 1982; Stene, 1940), em que as } \\
\text { pessoas na organização se tornam seus braços e pernas, ou seja, } \\
\text { hábitos não necessitam de pensamento, pois estes são automáticos } \\
\text { (Feldman \& Pentland, 2003). }\end{array}$ \\
\hline Rotinas como programas de desempenho & $\begin{array}{l}\text { A segunda metáfora trata as rotinas organizacionais como programas } \\
\text { de desempenho (Levitt et al., 1999) em que os procedimentos } \\
\text { operacionais padrão são os exemplos típicos de um programa de } \\
\text { desempenho que podem exigir processamento de hábitos, escolhas, } \\
\text { ramos, ou pontos de decisão. }\end{array}$ \\
\hline Rotinas como material genético & $\begin{array}{l}\text { A terceira metáfora de rotinas organizacionais origina-se no trabalho } \\
\text { de Nelson e Winter (1982), no qual se comparou as rotinas } \\
\text { organizacionais com material genético, ou seja, essas rotinas } \\
\text { desempenham o papel que os genes desempenham na teoria da } \\
\text { evolução biológica, pois os genes são uma característica presente no } \\
\text { organismo para determinar o seu possível comportamento, embora o } \\
\text { comportamento real seja determinado também pelo ambiente } \\
\text { (Nelson \& Winter, 1982). }\end{array}$ \\
\hline
\end{tabular}

Nota. Fonte: elaborado pelos autores baseado em Feldman, M. S., \& Pentland, B. T. (2003). Reconceptualizing organizational routines as a source of flexibility and change (96-97). Administrative Science Quarterly, 48(1), 94-118. doi: 10.2307/3556620 
Tendo em vista que as rotinas codificam as capacidades e os conhecimentos organizacionais, elas são consideradas como um componente fundamental da aprendizagem organizacional (Argote, 1999; March, 1991), podendo desempenhar o papel de memória da organização (Huber, 1991). Nesse sentido, apesar de as rotinas poderem ser uma fonte de inércia e rigidez, elas também podem ser fonte importante de flexibilidade e mudança (Feldman \& Pentland, 2003). Além disso, muitas organizações utilizam metarrotinas, tais como a melhoria contínua e gestão da qualidade total (Hackman \& Wageman, 1995), como um meio de gerar mudança. Metarrotinas têm sido consideradas como um mecanismo para a geração de capacidades dinâmicas (Tranfield \& Smith, 1998), ou seja, a capacidade inerente de toda a rotina organizacional para gerar mudança, apenas por seu desempenho em curso (Feldman \& Pentland, 2003).

Teorias existentes sobre as rotinas organizacionais relacionam a estabilidade e a mudança, considerando aspectos ostensivos e performativos, que estão estreitamente relacionados com os conceitos de estrutura e agência, como encontrado na teoria da estruturação (Giddens, 1984). Nesse sentido, os aspectos ostensivos são a forma ideal ou esquemática de uma rotina, pois é o abstrato, ideia generalizada da rotina, ou a rotina em princípio (Feldman \& Pentland, 2003). Já o aspecto performativo consiste em ações específicas, realizadas por pessoas específicas, em locais e horários específicos, ou seja, é a rotina na prática (Feldman \& Pentland, 2003). Dessa forma, Feldman e Pentland (2003) afirmam que esses aspectos são necessários para que uma rotina organizacional possa existir.

Conforme mencionado anteriormente, neste estudo foi utilizada a abordagem de Tsang e Zahra (2008), que aborda a desaprendizagem como o descarte de rotinas. Utiliza-se, também, o conceito de rotinas de Feldman e Pentland (2003), apresentado no início desta seção, bem como os aspectos ostensivo e performativo, igualmente discutidos aqui. Assim, para entender a desaprendizagem organizacional, utiliza-se uma abordagem baseada em rotinas, e o mesmo pode ser feito em relação à aprendizagem organizacional.

\section{Aprendizagem organizacional}

Argyris e Schon (1978) trazem um dos primeiros conceitos de aprendizagem organizacional, tratando-a como um processo de corrigir erros. Já Fiol e Lyles (1985) a conceituam como sendo o processo pelo qual se aprimoram as ações por meio do aumento do conhecimento e da compreensão. A teoria da aprendizagem organizacional faz referência a quatro diferentes níveis de aprendizagem, a saber: individual, grupal, organizacional e interorganizacional (Crossan, Lane, \& White, 1999; Knight, 2002; Wilson, Goodman, \& Cronin, 2007). Com isso, é possível perceber o caráter multidisciplinar do conceito de aprendizagem organizacional, pois esse foi desenvolvido a partir do conhecimento de diversas disciplinas: psicologia e desenvolvimento organizacional, ciência administrativa, sociologia e teoria organizacional, estratégia, gerenciamento da produção, antropologia cultural (Antal, Dierkes, Child, \& Nonaka, 2001; Easterby-Smith, 1997).

Alguns autores abordam a aprendizagem e a desaprendizagem organizacional como duas extremidades opostas, enquanto outros afirmam que desaprendizagem organizacional é precondição para a aprendizagem (Tsang \& Zahra, 2008). Caracterizam ainda que a "desaprendizagem é um subprocesso importante do processo de aprendizagem organizacional" (Akgün et al., 2007, p. 804). Nesse sentido, Srithika e Bhattacharyya (2009) afirmam que, na maioria dos casos, desaprendizagem precede a aprendizagem, exceto quando a aprendizagem ocorre pela primeira vez e não há nenhum conhecimento anteriormente adquirido. Porém, os mesmos autores alegam que a razão pela qual atualmente existem menos estudos sobre desaprendizagem em relação à aprendizagem poderia ser pelo fato de que a primeira é vista como conceitualmente subordinada à segunda (Srithika \& Bhattacharyya, 2009).

No estudo aqui descrito, considerou-se a aprendizagem organizacional a partir de uma visão baseada em rotinas, ou seja, a aprendizagem vista como a incorporação de rotinas na memória organizacional. 


\section{Memória organizacional}

Tanto aprendizagem quanto desaprendizagem organizacional estão relacionadas ao tema memória organizacional. De acordo com Walsh e Ungston (1991), a memória organizacional diz respeito às informações armazenadas a partir do histórico de uma organização e que podem ser utilizadas nas tomadas de decisões no presente, ou, simplesmente, é o meio pelo qual as organizações armazenam o conhecimento para sua utilização futura (Huber, 1991).

Para a aprendizagem ocorrer, as lições aprendidas necessitam ser incorporadas na memória de uma organização; já para desaprender, as rotinas de interesse devem ser removidas dessa mesma memória (Tsang \& Zahra, 2008). Akgün, Byrne, Lynn e Keskin (2007) pontuam que nos estudos analisados por eles, desaprendizagem, tanto em estudos de nível individual e organizacional, é: eliminação de memória via refutação; desmontagem das conexões e dos mecanismos da memória e/ou mudança da forma como a memória se manifesta. Assim, a desaprendizagem tem sido conceituada como a eliminação da memória organizacional (Akgün et al., 2007; Tsang \& Zahra, 2008). Porém, dado que desaprendizagem é um processo cognitivo, as alterações não cognitivas em artefatos organizacionais devem ser associadas às alterações nas crenças e rotinas para facilitar a desaprendizagem (Akgün et al., 2007).

Especificamente, Walsh e Ungston (1991) tratam a memória organizacional como formas de retenção ou caixas, que podem ser os indivíduos, a cultura, as transformações, as estruturas organizacionais, a ecologia e os arquivos externos (Walsh \& Ungston, 1991). Igualmente, identifica-se na literatura diversos tipos de meios de retenção de conhecimento na memória organizacional: arquivos (Campbell-Kelly, 1996), cultura (Cook \& Yanov, 1993; Sackman, 1992), indivíduos (Walsh \& Ungston, 1991), produtos (Hargadon \& Sutton, 1997; Olivera \& Argote, 1999), rotinas e regras de produção (Nelson \& Winter, 1982) e sistemas de informação baseados em computador (Huber, 1991).

As rotinas são gravadas na memória organizacional e envolvem aspectos ostensivos e performativos. $\mathrm{O}$ aspecto ostensivo de uma rotina diz respeito à possibilidade de armazená-la em ambas as caixas de armazenamento (humanas e não humanas), já o aspecto performativo, frequentemente, envolve apenas caixas de armazenamento humanas (Tsang \& Zahra, 2008).

Martin de Holan (2011), com foco em esquecimento, mas de forma complementar, relaciona o tema ao descarte de ativos e rotinas. O autor afirma que "ativos podem ser eliminados, substituídos, modificados, reorganizados e recombinados, e cada uma dessas ações tem o objetivo de introduzir modificações na forma como as coisas são feitas na organização" (Martin de Holan, 2011, p. 319). Em relação às rotinas, o autor menciona que assim como os ativos, elas podem ser modificadas de várias formas de modo a produzir resultados diferentes, mas também para parar de produzir certos resultados que eram produzidos antes por meio das rotinas descartadas (Martin de Holan, 2011).

Além disso, Walsh e Ungston (1991) relatam os principais processos relacionados com o funcionamento da memória organizacional, ou seja, aquisição, retenção e recuperação de conhecimento, e os tipos de conhecimento que se relacionam com o que, por que, quem, entre outros, que cada "caixa" poderia reter. Diante disso, esses autores desenvolveram proposições em relação à memória organizacional que envolvem diversos processos organizacionais, incluindo a tomada de decisões e gestão da mudança na organização (Casey \& Oliveira, 2011). Por fim, atualmente a memória organizacional também é trabalhada a partir de conhecimentos dispersos, por exemplo, realizada por pessoas e documentos e por mecanismos de integração que tornam os conhecimentos mais acessíveis (Oliveira, 2000).

De acordo com Tsang e Zahra (2008), os pesquisadores falham algumas vezes na distinção entre aprendizagem e desaprendizagem organizacional. Assim, uma clara linha de divisão entre os dois conceitos deve ser desenhada. Embora eles estejam intimamente relacionados, podendo ocorrer juntos, a aprendizagem pode ocorrer sem a desaprendizagem.

Nesse sentido, aprendizagem e desaprendizagem organizacional estão relacionadas entre si e com a memória organizacional (Akgün et al., 2007). Para a aprendizagem ocorrer, as lições aprendidas 
necessitam ser incorporadas na memória de uma organização; já para desaprender, as rotinas de interesse necessitam ser removidas desta mesma memória (Tsang \& Zahra, 2008). A partir de uma visão baseada em rotinas, pode-se visualizar os processos de aprendizagem e desaprendizagem organizacional, conforme Figura 1.

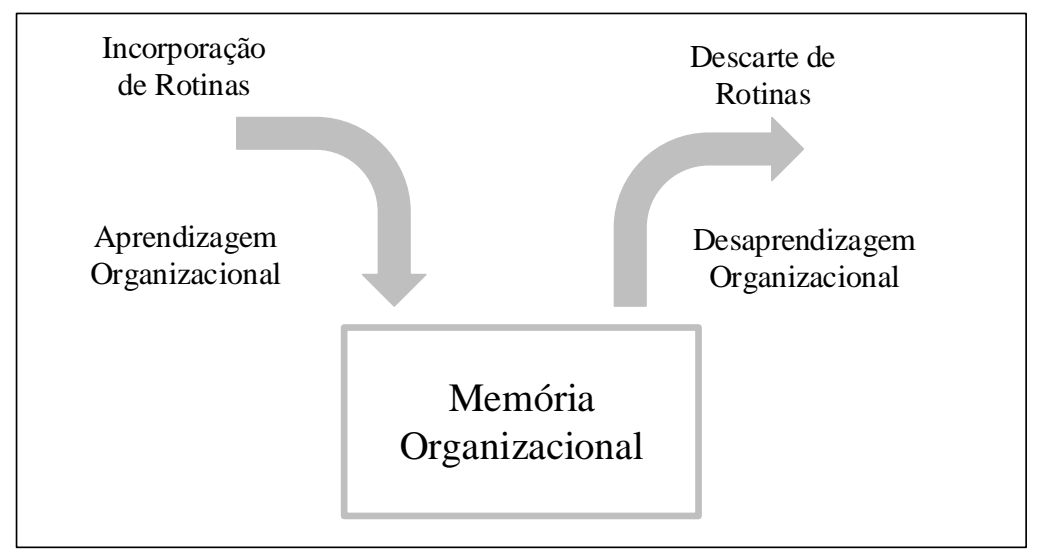

Figura 1. Aprendizagem, Desaprendizagem, Memória e Rotinas

Fonte: elaborado pelos autores.

Criação de novos e relevantes conhecimentos e livrar-se do conhecimento obsoleto e que já não é relevante são dois problemas cruciais que as organizações enfrentam na atualidade (Srithika \& Bhattacharyya, 2009). Muitas vezes a dificuldade na desaprendizagem individual constitui uma barreira significativa à aprendizagem organizacional (Tsang \& Zahra, 2008), principalmente em momentos de mudança contínua ou episódica, tratadas na próxima seção.

\section{Mudança organizacional}

Uma mudança na organização pode requerer dela processos de aprendizagem e/ou desaprendizagem, assim como estes podem provocar mudanças na organização. Hendry (1996), por meio da análise do conceito de mudança organizacional de outros autores, conclui que ela representa um termo genérico e é um conceito amplo que envolve análise, aprendizagem, educação e processo político, bem como um processo que combina elementos racionais, políticos e culturais. Para Nadler, Shaw e Walton (1995), mudança corresponde a uma resposta da organização às alterações que ocorrem no meio ambiente, visando preservar a congruência entre seus componentes, seja o trabalho, as pessoas, ou os arranjos organizacionais formais e informais.

Com base na literatura de mudança e de memória organizacional, Akgün et al. (2007) entendem que a desaprendizagem catalisa o processo de aprendizagem organizacional promovendo um processo de aprendizagem dinâmico. Apesar de a desaprendizagem estar incorporada ao processo de mudança, ela não tem como objetivo a melhoria de desempenho por si só; em vez disso, ela é um catalisador para o processo de mudança (Akgün et al., 2007).

As mudanças pelas quais uma organização passa podem ser contínuas ou episódicas. Na mudança contínua, os indivíduos, por vezes, podem variar as atividades relativas ao aspecto ostensivo de uma rotina para coincidir com o contexto específico em que se encontram (Tsang \& Zahra, 2008). Já a mudança episódica ocorre em certos períodos durante os quais as pressões para alterar são precipitadas por eventos externos, como descontinuidades tecnológicas ou eventos internos como a mudança na gestão de topo (Tsang \& Zahra, 2008).

Um conjunto de crenças fixas leva as organizações à rigidez de percepção ou atribuições causais imprecisas, sendo que esses resultados fazem com que elas se tornem lentas para reconhecer as alterações (Dickson, 1992). Em comparação com a mudança contínua, a mudança episódica é muitas vezes maior em escopo, mais estratégica no seu conteúdo, bem como mais deliberada e formal (Tsang \& Zahra, 2008). Muitas vezes uma crise é o gatilho da mudança episódica (Tsang \& Zahra, 2008). 


\section{Aspectos Metodológicos}

De forma a alcançar o objetivo deste estudo, inicialmente foi realizada uma revisão de literatura para aprofundar o contato com o tema, desaprendizagem organizacional, constatando-se a necessidade de mais estudos empíricos (Akgün et al., 2007; Srithika \& Bhattacharyya, 2009; Tsang \& Zahra, 2008). Nesse sentido, o estudo aqui descrito busca fornecer uma contribuição empírica ao tema, descrevendo o processo de aprendizagem organizacional em uma das Pró-Reitorias da Universidade Federal de Santa Catarina.

Para isso, definiu-se a utilização da abordagem qualitativa de pesquisa, ou seja, aquela capaz de analisar os aspectos implícitos no desenvolvimento das práticas de uma organização e a interação entre seus integrantes (Triviños, 1987). A decisão de se utilizar esta abordagem foi devido à possibilidade de explorar e entender o significado que os indivíduos ou os grupos atribuem a um problema social (Creswell, 2010). Para o planejamento e a posterior execução do estudo, utilizaram-se as dimensões propostas por Creswell (2010): estratégia de investigação, papel dos pesquisadores, procedimentos de coleta de dados, procedimentos de registro de dados, análise e interpretação dos dados, confiabilidade, validade e generalidade e relatório qualitativo.

Em relação à estratégia de investigação, utilizou-se a pesquisa de campo, que aqui se refere "à observação e à interação com as pessoas 'no seu habitat natural', no lugar específico da ação fora das paredes do laboratório" (Spink, 2003, p. 21). Para isso, escolheu-se uma das Pró-Reitorias existentes na Universidade Federal de Santa Catarina, que, por motivos de confidencialidade, não será citada. A amostragem utilizada foi a não probabilística, que é aquela que confia no julgamento pessoal do pesquisador, e não na chance de selecionar os elementos amostrais (Malhotra, 2001). Essa Pró-Reitoria foi escolhida por três motivos: (a) conveniência, já que se pôde contar com o apoio da administração do setor para a realização das entrevistas e para ter acesso aos documentos, além de um dos pesquisadores ser colaborador deste setor, o que auxiliou na coleta dos dados e nas observações; (b) existência de mudanças, principalmente em trocas de gestão, em que a literatura evidencia uma relação entre mudanças e desaprendizagem organizacional; e (c) importância do setor, tendo em vista que ele é um dos principais no contexto da universidade.

A Pró-Reitoria estudada, órgão executivo central, auxilia o Reitor em suas tarefas executivas em áreas de atuação da Universidade. Como instâncias de tarefas executivas, além do Pró-Reitor, a PróReitoria possui uma coordenação, uma comissão e quatro departamentos.

Em relação aos procedimentos de coleta de dados, foi utilizada a entrevista semiestruturada (procedimento principal), associada à utilização de documentos e à observação participante, realizada por um dos pesquisadores que é colaborador do setor (procedimentos complementares). É importante ressaltar que a participação de um dos pesquisadores no contexto pesquisado pode acabar influenciando os comportamentos dos indivíduos. Nesse sentido, buscou-se confrontar as respostas das entrevistas que contaram com a participação do pesquisador colaborador com as que não contaram com a participação do mesmo, a partir da relação de trabalho entre ele e os entrevistados. Como resultado disso, as observações realizadas pelo pesquisador colaborador seguiram padrões anteriormente observados por ele, o que sugere que os comportamentos dos observados não foram influenciados pela sua participação no estudo.

Em relação às entrevistas, essas foram realizadas com seis funcionários pertencentes ao quadro da Pró-Reitoria pesquisada. Os cargos ocupados por esses funcionários e o tempo que os mesmos possuem no setor são: analista de tecnologia da informação (11 anos); coordenador de apoio administrativo (3 anos); assistente em administração (10 meses); administradora (1 ano e 8 meses); técnica em assuntos educacionais ( 4 anos) e pedagoga ( 1 ano e 8 meses).

A escolha dos entrevistados, além da disponibilidade dos mesmos, considerou prioritariamente abranger diferentes funções dentro do setor. Dentro do quadro funcional do setor, optou-se por entrevistar pessoas ligadas às três grandes áreas de processos que são geridos pela Pró-Reitoria estudada: 
tecnologia da informação, administrativa e pedagógica. Nesse sentido, buscou-se uma maior representatividade dos fenômenos estudados. Uma vez que alguns dos entrevistados ocupam cargos únicos no setor, optou-se por não utilizar nenhuma identificação dos mesmos. Porém, ao longo da apresentação dos resultados, os códigos de identificação das falas transcritas são apenas para o relacionamento entre elas.

As entrevistas foram realizadas na própria Pró-Reitoria no mês de maio de 2013, durante dois dias. Inicialmente, além de informar aos entrevistados a questão de anonimato da pesquisa, foram apresentados a eles os conceitos básicos relativos à desaprendizagem organizacional com o intuito de minimizar possíveis ruídos de comunicação durante as entrevistas. De forma a guiar as entrevistas, foi utilizado um roteiro semiestruturado de perguntas. As perguntas do roteiro estavam divididas em quatro partes: questões gerais (abordando questões como cargo, função, tempo de serviço do entrevistado); rotinas (abordando aspectos relacionados à implementação e ao descarte de rotinas, como critérios de avaliação das rotinas, autonomia de gestores e funcionários para a implementação e descarte); pessoas (abordando aspectos relacionados à interação entre as pessoas e à implementação e descarte de rotinas, como aceitação e abertura da chefia para esses processos); e memória organizacional (abordando aspectos relacionados a armazenamento e descarte de rotinas na memória organizacional, como mecanismos e estratégias de armazenamento).

Em relação aos documentos, utilizaram-se documentos de âmbito geral, como o organograma e o histórico da Pró-Reitoria, para a caracterização do setor. E, em relação à observação participante, esta foi utilizada para auxiliar na análise e interpretação dos dados coletados nas entrevistas e nos documentos.

Para o registro dos dados das entrevistas foi utilizado um gravador. Uma vez gravadas, as entrevistas foram transcritas, obtendo-se trinta laudas. Os documentos foram coletados de forma física e digital, conforme disponibilidade. As observações do pesquisador colaborador do setor foram descritas em documento próprio. As observações previamente descritas seguiram o mesmo roteiro utilizado nas entrevistas. Além disso, o pesquisador colaborador do setor inferiu sobre os resultados das análises realizadas pelos demais pesquisadores e essas inferências foram adicionadas aos resultados do estudo.

A análise e a interpretação dos dados foram realizadas inicialmente sobre as transcrições das entrevistas. De forma complementar, foram adicionados os dados obtidos a partir de observação participante e dos documentos. As transcrições foram analisadas por meio de análise de conteúdo, que corresponde a "um conjunto de técnicas de análise das comunicações que utiliza procedimentos sistemáticos e objetivos de descrição do conteúdo das mensagens" (Bardin, 2002, p. 38). Para a análise do conteúdo foram utilizados os passos propostos por Creswell (2010): organização do material com a transcrição das entrevistas, leitura das transcrições para evidenciar padrões, agrupamento do material por temas, organização do material codificado para criar uma sequência lógica, descrição dos temas, interpretação e extração de significado com base na literatura, nas observações e nos documentos analisados. A análise dos dados foi realizada prioritariamente pelos pesquisadores que não são colaboradores do setor estudado, sendo que o colaborador contribuiu com as confirmações e sugestões sobre as análises.

A Tabela 2 apresenta os conceitos constitutivos e operacionais utilizados no estudo. 
Tabela 2

\section{Definições Constitutivas e Operacionais}

\begin{tabular}{|c|c|c|}
\hline Constructo & Definição Constitutiva & Definição operacional \\
\hline $\begin{array}{l}\text { Desaprendizagem } \\
\text { organizacional }\end{array}$ & $\begin{array}{l}\text { Desaprendizagem organizacional se refere ao } \\
\text { processo de descarte intencional de rotinas, } \\
\text { podendo abrir espaço para outras, se for o caso } \\
\text { (Tsang \& Zahra, 2008). }\end{array}$ & $\begin{array}{l}\text { Identificação de: } \\
\text {. descarte de rotinas; } \\
\text {. intencionalidade no descarte. }\end{array}$ \\
\hline Rotinas organizacionais & $\begin{array}{l}\text { Rotinas organizacionais são "um padrão } \\
\text { repetitivo e identificável de ações } \\
\text { interdependentes envolvendo múltiplos atores" } \\
\text { (Feldman \& Pentland, 2003, p. 96). Uma rotina é } \\
\text { composta por aspectos ostensivos e } \\
\text { performativos. Os aspectos ostensivos são a } \\
\text { forma ideal ou esquemática de uma rotina, pois é } \\
\text { o abstrato, ideia generalizada da rotina, ou a } \\
\text { rotina em princípio. Já o aspecto performativo } \\
\text { das rotinas consiste em ações específicas, por } \\
\text { pessoas específicas, em locais e horários } \\
\text { específicos, ou seja, é a rotina na prática. } \\
\text { (Feldman \& Pentland, 2003) }\end{array}$ & $\begin{array}{l}\text { Identificação de: } \\
\text {. ações na organização; } \\
\text {. aspectos ostensivo e } \\
\text { performativo dessas ações. }\end{array}$ \\
\hline Memória organizacional & $\begin{array}{l}\text { A memória organizacional diz respeito às } \\
\text { informações armazenadas a partir do histórico de } \\
\text { uma organização e que podem ser utilizadas nas } \\
\text { tomadas de decisões no presente ou, } \\
\text { simplesmente, é o meio pelo qual as organizações } \\
\text { armazenam o conhecimento para sua utilização } \\
\text { futura (Huber, 1991; Walsh \& Ungston, 1991) }\end{array}$ & $\begin{array}{l}\text { Identificação de: } \\
\text {. rotinas formalizadas na } \\
\text { organização. }\end{array}$ \\
\hline $\begin{array}{l}\text { Aprendizagem } \\
\text { organizacional }\end{array}$ & $\begin{array}{l}\text { Aprendizagem organizacional é o processo pelo } \\
\text { qual se aprimoram as ações por meio do aumento } \\
\text { do conhecimento e da compreensão (Fiol \& } \\
\text { Lyles, 1985). }\end{array}$ & $\begin{array}{l}\text { Identificação de: } \\
\text {. incorporação de rotinas. }\end{array}$ \\
\hline Mudança organizacional & $\begin{array}{l}\text { Mudança corresponde a uma resposta da } \\
\text { organização às alterações que ocorrem no meio } \\
\text { ambiente, visando preservar a congruência entre } \\
\text { seus componentes, seja o trabalho, as pessoas, ou } \\
\text { os arranjos organizacionais formais e informais } \\
\text { (Nadler, Shaw, \& Walton, 1995). }\end{array}$ & $\begin{array}{l}\text { Identificação de: } \\
\text {. eventos internos e/ou externos } \\
\text { seguidos de alteração } \\
\text { (incorporação e/ou descarte) } \\
\text { de rotinas da organização. }\end{array}$ \\
\hline
\end{tabular}

Nota. Fonte: elaborados pelos autores.

Em relação ao papel dos pesquisadores, além da condução da pesquisa, os pesquisadores participaram ativamente da coleta, análise dos dados e discussão dos resultados. Especificamente em relação às entrevistas, essas foram realizadas sempre por dois pesquisadores. Coube a um dos pesquisadores a condução das entrevistas e, ao outro, a anotação de observações e aspectos importantes das respostas dos entrevistados. Conforme mencionado, um dos pesquisadores é colaborador da PróReitoria pesquisada. Assim, esse pesquisador contribuiu para o estudo através de dados de observação participante.

Já em relação à confiabilidade, validade e generalidade, procurou-se utilizar estratégias adequadas ao contexto do estudo realizado. Para garantir a confiabilidade, foram utilizadas as recomendações de Yin (2010), sendo que todos os procedimentos realizados ao longo da pesquisa foram registrados em documentos à parte, inclusive constando as considerações dos pesquisadores responsáveis pelas entrevistas e daqueles que contribuíram com dados oriundos da observação participante. Além disso, as entrevistas foram transcritas também em documentos à parte, incluindo 
perguntas extras realizadas durante as seções. No que diz respeito à validade, utilizaram-se duas estratégias propostas por Creswell (2010): triangulação e verificação dos membros. Assim, para a triangulação de conteúdo, procurou-se associar às análises, além dos dados coletados por meio das entrevistas, dados a partir da observação participante de um dos pesquisadores, bem como dados oriundos de documentos.

Para a verificação dos membros, os resultados das análises foram discutidos com os participantes das entrevistas de modo que os mesmos puderam propor melhorias e correções aos resultados encontrados. Em relação à generalização, considera-se, de acordo com Yin (2010), que o presente estudo de campo não possibilita a generalização dos resultados, apenas pode fornecer uma contribuição empírica ao estudo do tema, e que essa pode ser complementada por outros estudos relacionados.

Finalmente, com relação ao relatório, procurou-se evidenciar, a partir da realidade estudada, os preceitos encontrados na literatura e abordados na fundamentação teórica apresentada. Além disso, os dados são apresentados na seção a seguir de forma descritiva, procurando seguir a ordem da revisão anteriormente apresentada. Busca-se, dessa forma, facilitar o entendimento das análises e dos resultados obtidos. Quando conveniente para os resultados, são apresentadas algumas falas dos entrevistados de forma a exemplificar a descrição realizada.

\section{Apresentação dos resultados}

Os resultados das entrevistas realizadas com os funcionários do setor foram agrupados em categorias emergentes a partir da análise do conteúdo das entrevistas, a saber: mudanças e descarte de rotinas, o descarte de rotinas no dia a dia do setor, processos de descarte e incorporação de rotinas, o papel das pessoas e proteção das rotinas na memória organizacional.

\section{Mudanças e descarte de rotinas}

De forma geral, os entrevistados relataram que quando ocorrem as mudanças de chefia, ocorrem mudanças nas rotinas. Nesse sentido, Lima e Bressan (2003) abordam que qualquer alteração, planejada ou não, nos componentes organizacionais - pessoas, trabalho, estrutura formal, cultura - ou nas relações entre a organização e seu ambiente, pode ter consequências relevantes, de natureza positiva ou negativa, para a eficiência, eficácia e/ou sustentabilidade organizacional.

O motivo das mudanças, segundo os funcionários, é que uma nova chefia, em geral, tem um perfil diferente da anterior e tende a olhar as rotinas atuais sob um novo ponto de vista.

“Cada gestão quer impor seus métodos e formas de pensar e, desta forma, todos devem aprender as novas rotinas e descartar outras" (E3).

Foi verificado que alguns dos entrevistados têm uma percepção de mudança maior que outros. Essa diferença está basicamente fundamentada no fato de que algumas áreas são mais relacionadas a processos definidos internamente (mudam mais) e outras são mais relacionadas a processos que dependem de definição de terceiros, por exemplo, legislações da Universidade (mudam menos).

"[Nas mudanças de chefia] algumas coisas que eram feitas de determinado jeito passaram a ser de outro, mas a rotina burocrática pesada não tem como mudar, a forma de abordagem é que muda um pouco" (E2).

Porém, de um modo geral, as mudanças de rotinas estão relacionadas às tentativas de melhoria de processos e podem ser uma demanda própria do setor ou de outros setores da Universidade. Sobre a forma de descarte das rotinas durante as mudanças de chefia, os entrevistados relataram que isso ocorre de forma gradual, à medida em que a chefia vai conhecendo os processos e rotinas do setor.

“Como nós só tivemos uma reunião de planejamento, então ... durante o próprio dia a dia eu apresentava as tarefas que eram executadas e a chefia me pedia que fosse mudado ou que não fizesse mais aquilo de determinado jeito, mas não existe nada oficializado em reunião ou em documento, nada” (E2). 
Especificamente sobre as rotinas descartadas nas mudanças de chefia, os funcionários percebem que, em geral, elas são substituídas por outras. Isso acontece na maior parte dos casos em função da atualização de um determinado processo para adequá-lo às exigências legais ou operacionais ou à inserção de uma nova tecnologia na Universidade ou especificamente na Pró-Reitoria. Nesse sentido, Tushman e Anderson (1986) afirmam que as mudanças são, em parte, o resultado do crescimento do mercado ou do desenvolvimento de tecnologias, e elas criam turbulências que podem destruir as competências existentes de uma organização. Acontece também, segundo os funcionários, de um conjunto de rotinas ser apenas alterado ou transferido para um outro setor da Universidade. Nesse caso, os executores das rotinas deixam de fazê-las, não ocorrendo um processo de desaprendizagem organizacional.

“Algumas foram substituídas e outras não. Algumas foram descartadas ou incorporadas por outro setor” (E2).

“Geralmente sim [ocorre descarte de rotinas], já que a cada nova gestão, os novos gestores possuem níveis de aprendizado e métodos de trabalhar. Com isso, geralmente há a implantação de novas rotinas e/ou substituição de outras" (E3).

Em relação à autonomia de gestores e funcionários para o descarte e alteração de rotinas, ela é variável conforme o tipo de rotina e a profundidade da alteração a ser realizada. Porém, de forma geral, funcionários e gestores buscam formalizar as alterações, com vistas a evitar problemas de falta de ajustamento, ou seja, desalinhamento com as normas e padrões do setor.

\section{O descarte de rotinas no dia a dia do setor}

Em relação ao descarte de rotinas, em alguns casos, os funcionários relataram que elas foram simplesmente descartadas, sem a incorporação de outras. Esses casos acontecem, por exemplo, quando um determinado processo é avaliado como desnecessário para o setor.

"Tem muitas [rotinas apenas descartadas]. Por exemplo, a rotina de fazer um seguro, porque não existe um sistema de seguro da Universidade, e eu fazia para o [setor] estágio, além de umas pequenas coisas que tinha aqui. Eu fazia uma rotina de seguro, o que não é utilizado mais, [então] foi descartada simplesmente, porque a instituição parece que absorveu isso" (E1).

Os funcionários também relataram que as rotinas são descartadas ou alteradas geralmente em conversas com as chefias ou por meio de documentos ou outros comunicados formais. Em geral, os funcionários afirmam que não existem processos formais de avaliação do descarte e incorporação de rotinas. Segundo eles, a avaliação é realizada pelos próprios funcionários no dia a dia dos processos no setor.

Quando perguntados se houve rotinas que eram consideradas efetivas e que tiveram que ser descartadas, os funcionários não mencionaram nenhuma situação em que isso aconteceu. Porém, quando perguntados se as rotinas que haviam sido descartadas tiveram, posteriormente, que ser reincorporadas, houve relatos de que isso já aconteceu. Aborda sobre isto Azmi (2008) afirmando que "para que uma organização possa obter sucesso, ela precisa aprender, desaprender e, em seguida, reaprender. $\mathrm{O}$ processo de desaprendizagem deve ser seguido pelo processo de reaprendizagem" (p. 249).

A visão apresentada pelo analista de TI, por ele estar relacionado ao desenvolvimento e alteração de sistemas, fornece uma ideia de como as rotinas são descartadas e retomadas no setor. Segundo ele, muitas rotinas são retomadas, o que exige alteração em sistemas. Relacionando as rotinas organizacionais com procedimentos de software, ele menciona que há um banco de dados desses procedimentos e que em alguns casos aproveita procedimentos que haviam sido abandonados, pois surgem novas situações em que eles devem ser retomados. Os demais funcionários também citaram situações em que antigas rotinas foram retomadas. Na maior parte dos casos, segundo eles, verifica-se que um novo processo, por exemplo, não é tão efetivo quanto o anterior.

Quanto às rotinas esquecidas, os funcionários relataram que em muitos casos isso acontece. No geral, os motivos estão relacionados à falta de tempo para a execução da rotina. Quando isso acontece 
com certa frequência, os funcionários acabam tendo dificuldade de descrever e, consequentemente, executar a rotina. A falta de tempo foi relacionada, por alguns dos entrevistados, com a falta de funcionários para o desempenho das funções.

\section{Processos de descarte e incorporação de rotinas}

Os funcionários, grupos ou chefias podem demonstrar o interesse no descarte ou na alteração de rotinas, conforme Tabela 3.

Tabela 3

Níveis de Interesse no Descarte e Alteração de Rotinas

\begin{tabular}{ll}
\hline Níveis & Descrição \\
\hline Funcionários & No nível individual, o interesse pelo descarte de rotinas pode se dar de duas formas: \\
& . O funcionário deixa simplesmente de executar a rotina: os motivos para isso podem estar \\
& relacionados à falta de conhecimento da execução da rotina, falta de entendimento de sua \\
& importância, identificação de que a rotina não é efetiva ou o recebimento de uma \\
& comunicação formal da chefia. \\
& . O funcionário executa a rotina, mas a questiona: o funcionário pode não entender a \\
& importância da rotina ou identificar que ela não é efetiva, mas continua a executá-la para \\
& seguir as diretrizes organizacionais. \\
& Nos dois casos o funcionário pode ou não discutir com colegas e com a chefia sobre a rotina. \\
& No nível grupal, pode levar ao conhecimento da rotina e à identificação de que a rotina não é \\
efetiva, quando: & . O funcionário passa a conhecer a execução da rotina ou a importância dela e então passa a \\
Grupal & executá-la. \\
& O funcionário pode convencer o grupo de que a rotina não é efetiva, gerando um \\
& entendimento mútuo da não efetividade. \\
& Nos dois casos as chefias podem ser envolvidas. \\
\hline As chefias podem perceber que uma rotina não é mais necessária ou deve ser alterada. Isso \\
pode acontecer por demandas internas (discussão com indivíduos ou grupos sobre a rotina) ou \\
demandas externas (legislação, por exemplo). Nesse caso, o descarte ou alteração tende a ser \\
formalizado e comunicado aos grupos e indivíduos.
\end{tabular}

Nota. Fonte: Dados da pesquisa.

Os três níveis citados se relacionam, uma vez que a não execução da rotina pode gerar dúvidas quanto a sua efetividade, o que pode ser discutido com colegas, e, em última instância, chegar às chefias, podendo fazer com que a organização formalize o descarte ou a alteração da rotina. Porém, mesmo que as chefias formalizem tal descarte ou alteração, é possível que estes não sejam institucionalizados, uma vez que indivíduos ou grupos de indivíduos podem manter padrões anteriores ou de não aceitação de novos.

Em relação à implementação de novas rotinas e alteração ou à troca de rotinas existentes, os funcionários relataram que, em geral, existe algum tipo de resistência. Essa resistência, segundo eles, está relacionada com o apego ao conhecimento já adquirido, e ocorre em muitos casos quando as novas rotinas estão relacionadas ao uso de novas tecnologias.

"Sim, principalmente em relação a alguma nova tecnologia. Não modifica sua rotina, incorporando novas coisas porque não quer" (E4).

“Acredito que, como é próprio do ser humano resistir ao novo, pelo fato que é mais confortável ficar fazendo aquilo que já domina, que está sob o seu controle, até acontece” (E5). 
Akgün et al. (2007) abordam que a desaprendizagem envolve a combinação das mudanças nas crenças e rotinas, sendo que a desaprendizagem não ocorre de forma eficaz sem que esses dois elementos se modifiquem. Corroboram Wong, Cheung, Yiu e Hardie (2012) quando abordam que a desaprendizagem é analisada pela mudança de crenças e de rotinas. Isso pode explicar o motivo pelo qual desaprender representa um desafio para as organizações.

De acordo com os entrevistados, algumas rotinas acabam sendo abandonadas simplesmente pela falta de execução dos funcionários. Porém, isso acontece em geral com aquelas cuja execução pode melhorar o desempenho, mas cuja não execução não traz nenhum inconveniente de imediato.

"Na realidade, tem as rotinas que são viáveis, que não tem como abandonar, senão a coisa não anda, e tem rotinas que são para melhorar, mas se as pessoas fazem ou não, não sei, mas as pessoas não reclamam para mim" (E1).

Com relação ao estabelecimento de novas rotinas, segundo os entrevistados, tanto para a incorporação quanto para o descarte, os processos são os mesmos, e, muitas vezes, eles se confundem por serem realizados concomitantemente ou terem uma relação de dependência. De acordo com os entrevistados, não existem processos formalizados e as formas de incorporação e descarte são contingenciais. Em alguns casos, são utilizadas reuniões, confecção de manuais ou simplesmente há uma conversa com os responsáveis.

Sobre a necessidade de desaprender para dar lugar a um novo aprendizado, ou seja, descartar rotinas para a incorporação de novas, os entrevistados afirmaram que é comum que isso aconteça. Inclusive eles foram capazes de relatar diversas ocasiões em que isso aconteceu.

"Quando eu entrei aqui, eu vim para fazer uma atividade que não é a de agora. Era para trabalhar com outra
servidora e eu vim de outra Instituição. Então eu fazia os procedimentos de uma forma. Eu trabalhava de um
jeito e a estrutura era outra. Então, quando eu cheguei aqui, eu tive que aprender tudo de novo e esquecer
aquilo, porque se eu continuasse pensando daquela forma, eu não ia conseguir entender a situação aqui" (E4).

Nesse sentido, aprendizagem e desaprendizagem organizacionais estão intimamente ligadas. Sobre este fato, pode-se citar a posição de Tsang e Zahra (2008), abordando que alguns autores colocam a aprendizagem e a desaprendizagem organizacional como duas extremidades opostas, enquanto outros afirmam que desaprendizagem organizacional é precondição para a aprendizagem. Akgün et al. (2007), por exemplo, apresentam a desaprendizagem organizacional como um subprocesso importante do processo de aprendizagem organizacional.

Os entrevistados relataram que, na incorporação e no descarte de rotinas, é comum haver resistências das pessoas envolvidas, e que essa depende do grau de alteração. Mas nenhum deles soube relatar algum caso grave em que as pessoas simplesmente se recusaram a incorporar ou descartar rotinas. Foram, em geral, casos isolados e que não colocaram em risco o trabalho do setor.

Em relação à sugestão dos funcionários, os entrevistados foram unânimes em afirmar que existem meios pelos quais as pessoas podem sugerir alterações nas rotinas. Segundo eles, os meios são informais, porém têm funcionado a contento. Normalmente as sugestões são realizadas verbalmente e existe um momento de convencimento dos pares ou chefia, justificando as melhorias que a mudança pode trazer.

\section{O papel das pessoas}

Os entrevistados não relataram problemas relacionados às rotinas que os funcionários vindos de outros setores ou organizações trazem para o setor estudado, ou seja, relacionados à incorporação de antigas rotinas que de alguma forma não estão adequadas ao contexto do setor. Os prejuízos advindos da incorporação dessas rotinas podem ser prolongados pela resistência à mudança, uma vez que as pessoas tendem a querer manter as rotinas organizacionais com as quais estão acostumadas (Tsang, 2008). 
Na mesma linha, a maior parte dos entrevistados afirmou que o fator que mais pesa no aumento da resistência à mudança é a idade e o tempo de trabalho da pessoa. Segundo eles, aqueles que estão há mais tempo executando um determinado conjunto de rotinas têm, em geral, maior resistência à mudança. Esse fato pode ocorrer tendo em vista que as rotinas organizacionais são executadas por pessoas, as quais possuem suas ações motivadas pelas vontades e pelas intenções (Feldman, 2000). Dessa forma, elas criam, resistem e se envolvem em conflitos, podendo influenciar as rotinas organizacionais, criando um enorme potencial de mudanças (Feldman, 2000). Assim, é possível que, pelo fato de os funcionários com mais tempo de trabalho terem menos motivações para mudar e inovar, sua resistência às mudanças seja maior quando comparada a dos funcionários mais novos.

A unanimidade dos entrevistados relatou que existem diferenças de postura entre as pessoas, tanto para a incorporação quanto para o descarte de rotinas. Essas diferenças podem não estar apenas relacionadas ao indivíduo, mas também ao contexto, uma vez que a resistência não é uniforme e varia de indivíduo para indivíduo de acordo com a fase do processo de mudança (Watson, 1969).

Para Becker, Hyland e Acutt (2006), as maiores motivações para fomentar a desaprendizagem são a inclusão de novas informações ou comportamentos e a promoção da aprendizagem, da mudança e da inovação. Entretanto, para que isso ocorra, deve-se reduzir a resistência à mudança. Nesse sentido, foi mencionado pelos funcionários que ações que a reduzem estão relacionadas à sensibilização dos envolvidos nesse processo.

Outro ponto relatado pelos funcionários é que, em geral, por haver certa carência de formalização dos processos, o funcionário novo é quem acaba buscando as formas de execução das rotinas do setor, contando normalmente com colegas para o aprendizado. Isso pode fazer com que um conjunto de rotinas acabe se perpetuando na organização, uma vez que o aspecto ostensivo das rotinas é negligenciado pela gestão, seja pela falta de formalização ou até mesmo de capacitação formal dos novos funcionários. Nesse sentido, o desafio da desaprendizagem organizacional muitas vezes se encontra em apagar o conteúdo das caixas de armazenamento humanas (Tsang \& Zahra, 2008).

\section{Proteção das rotinas organizacionais na memória organizacional}

Os entrevistados relataram que não existem estratégias formalizadas para a proteção das rotinas organizacionais na memória organizacional, tanto nas mudanças de chefia quanto nas mudanças e chegadas de funcionários.

"Deveria haver uma ferramenta pra, quando alguém sair, o outro ter acesso às informações. Quando a professora $\mathbf{X}$ saiu, não passou nada. Agora está a professora $\mathbf{Y}$, antes dela estava o $\mathbf{Z}$ que saiu. $\mathbf{O}$ que tinha que existir, na realidade, é que na transição existisse um processo em que os que vão entrar trabalhassem com aqueles que estão há um período, como se fosse uma passagem de bastão em que o cara corre meio junto uma parte. Senão dá uma descontinuidade enorme" (E1).

As estratégias citadas pelos entrevistados foram mencionadas como próprias das pessoas ou de grupos específicos e não da organização. As duas estratégias mais comuns são a utilização de arquivos de computador com acesso pelos envolvidos na rotina e a passagem informal das informações de um funcionário mais antigo (ou que está deixando a função) para outro.

"Por exemplo, a T era muito organizada e acabou colocando no papel algumas das rotinas, mas como te falei, quando eu entrei e a outra menina saiu, o que ela lembrou, ela me passou, mas a rotina que aprendi foi no peito" (E2).

Quanto a mecanismos para a transferência de conhecimento quando determinada pessoa deixa o setor, os entrevistados afirmaram que não existe algo institucionalizado, e que depende fundamentalmente da vontade da pessoa que está saindo em transferir parte do que sabe para outras pessoas do setor ou para a pessoa que vai ocupar o seu lugar. Um dos entrevistados citou que a utilização de manuais em seu departamento tem auxiliado a transferência de conhecimento, mas que essa ação é complementada com a postura ativa das pessoas, uma vez que nem todo conhecimento está explicitado. 
"Somente quando há a iniciativa de quem for sair em deixar um manual com os procedimentos específicos da área de atuação. Caso contrário, o novo servidor deve correr atrás para saber como deve ser feito tal procedimento" (E3).

Ainda nesse sentido, os entrevistados também afirmaram que não existem estratégias específicas em relação ao conhecimento armazenado. Inclusive muitas das rotinas estão apenas em caixas de armazenamento humanas, o que faz com que ocorram perdas de desempenho quando um funcionário mais antigo sai do setor, seja por transferência ou aposentadoria.

Em relação aos meios não humanos de armazenamento de conhecimento, os entrevistados citaram como principal meio físico o papel (manuais e documentos, por exemplo) e, como principal meio tecnológico, arquivos de computador (planilhas e manuais, por exemplo).

Os entrevistados citaram exemplos de ocasiões em que eles e seus colegas tiveram dificuldade na incorporação de novas rotinas. Um dos entrevistados citou a implantação de um novo sistema de informação, momento no qual, segundo ele, muitos reclamaram da mudança e tiveram que ser obrigados, por instâncias superiores, a utilizar o sistema. Após o período de adaptação, segundo os entrevistados, as pessoas passaram a perceber que o sistema facilitou os processos.

Os entrevistados relataram que, em algumas situações, a saída de uma determinada pessoa do setor acaba provocando alguma queda no desempenho, principalmente se a pessoa tem muita experiência sobre um determinado assunto. Nesse sentido, a falta de mecanismos de transferência de conhecimentos acaba determinando as dificuldades que as pessoas envolvidas enfrentam. Corrobora Tsang (2008) quando afirma que, no contexto da transferência do conhecimento, aprendizagem e desaprendizagem são processos distintos. As ações em cada estágio de transferência são diferentes para a aprendizagem e desaprendizagem.

\section{Considerações Finais}

O presente trabalho teve como objetivo abordar a questão da desaprendizagem organizacional em uma das Pró-Reitorias da Universidade Federal de Santa Catarina. Entende-se a importância do trabalho, uma vez que foram encontrados poucos estudos que abordassem o tema em instituições públicas e, mais especificamente, em instituições de ensino. Ainda, considera-se que a criação de novos e relevantes conhecimentos e o descarte dos obsoletos, que já não são mais relevantes, são dois problemas cruciais que as organizações enfrentam na atualidade (Srithika \& Bhattacharyya, 2009).

Como resultados, verificou-se que as mudanças, sejam elas gerais ou específicas, profundas ou superficiais, estão relacionadas aos fenômenos de aprendizagem e desaprendizagem. As mudanças, em alguns casos, podem exigir aprendizagem e desaprendizagem, e são momentos propícios para que esses fenômenos possam acontecer. O contrário também pode acontecer. No caso específico da desaprendizagem, apesar de esse fenômeno estar incorporado ao processo de mudança organizacional, ele não tem como objetivo a melhoria de desempenho por si só; em vez disso, ele é um catalisador para o processo de mudança (Akgün et al., 2007).

No setor estudado, não foram identificadas estratégias formalizadas para a memória organizacional, tampouco para a aprendizagem e desaprendizagem. Porém, identificaram-se ações individuais nesse sentido, favorecendo a visão de que as pessoas, de um modo geral, têm a noção da importância do conhecimento para o desempenho de suas funções. Assim, a institucionalização de ações de gestão do conhecimento poderá favorecer o desempenho da organização.

A partir da percepção dos autores da pesquisa aqui relatada, sugerem-se alguns pontos para futuros estudos relacionados à desaprendizagem organizacional. Uma vez que durante o estudo encontrou-se, apesar da íntima relação, dificuldade em separar aprendizagem e desaprendizagem organizacionais, recomenda-se estudos que possam delimitar de forma mais clara a relação entre esses 
constructos. Tal dificuldade foi também destacada por Tsang e Zahra (2008). Estudos com esse objetivo poderiam facilitar outros trabalhos empíricos sobre aprendizagem, desaprendizagem e a relação entre os dois fenômenos.

Uma vez que se verificou, no caso pesquisado, que não existem estratégias para evitar o esquecimento organizacional, recomendam-se estudos empíricos que possam abordar com mais profundidade esse fenômeno, relacionando-o também com a perda de conhecimento.

Especificamente no caso da Universidade, recomendam-se estudos que possam verificar de forma mais ampla a questão da desaprendizagem organizacional. Esses estudos poderiam favorecer o entendimento do fenômeno na Universidade, em específico, e em instituições públicas, em geral.

Apesar de os resultados não poderem ser generalizados para toda a Universidade, eles podem fornecer uma ideia de como ocorre a desaprendizagem organizacional na instituição e podem também servir de base para futuras pesquisas sobre o tema. Assim, de um modo geral, salienta-se a importância da desaprendizagem organizacional para as organizações, sejam elas privadas ou públicas. Além disso, novos estudos empíricos devem ser desenvolvidos aproveitando a teoria já existente na literatura para verificar os diferentes relacionamentos e peculiaridades da desaprendizagem organizacional no âmbito das organizações.

Embora a pesquisa aqui descrita aumente o conhecimento empírico sobre o fenômeno da desaprendizagem organizacional, algumas limitações devem ser mencionadas. Apesar de terem sido tomadas medidas para atenuar riscos do uso, mesmo que complementar, da observação participante, possíveis vieses dos respondentes podem ter influenciado o estudo. Ainda, o número reduzido de funcionários entrevistados impossibilita a generalização dos resultados. Estudos futuros podem ampliar o número de funcionários e setores, utilizando, por exemplo, uma amostragem por clusters.

O fato de os fenômenos da aprendizagem e desaprendizagem organizacional estarem intimamente ligados, e a consequente dificuldade em separá-los durante as entrevistas e as análises, foi uma das dificuldades encontradas no estudo. A abordagem baseada em rotinas auxiliou essa separação, porém, entende-se que ela funciona também como um limitador do estudo, uma vez que a inclusão de outras abordagens poderia fornecer uma visão mais ampla do contexto.

\section{Agradecimentos}

Os autores agradecem aos avaliadores da Revista de Administração Contemporânea pela contribuição significativa para a melhoria do presente trabalho.

\section{Referências}

Akgün, A. E., Byrne, J. C., Lynn, G. S., \& Keskin, H. (2007). Organizational unlearning in beliefs and routines in organizations. Journal of Organizational Change Management, 20(6), 794-812. doi: $10.1108 / 09534810710831028$

Antal, A. B., Dierkes, M., Child, J., \& Nonaka, I. (2001). Organizational learning and knowledge: reflections on the dynamics of the field and challenges for the future. In M. Dierkes, B. Ariane, J. Child, \& I. Nonaka (Eds.), Handbook of organizational learning and knowledge (pp. 921-939). New York: Oxford University Press.

Argote, L. (1999). Organizational learning: creating, retaining, and transferring knowledge. Norwell, MA: Kluwer Academic Publishers. 
Argyris, C., \& Schön, D. A. (1978). Organizational learning: a theory of action perspective. Reading, MA: Addison-Wesley.

Azmi, F. T. (2008). Mapping the learn-unlearn-relearn model: imperatives for strategic management. European Business Review, 20(3), 240-259. doi: 10.1108/09555340810871437

Bardin, L. (2002). Análise de conteúdo. Lisboa: Edições 70.

Becker, K., Hyland, P., \& Acutt, B. (2006). Considering unlearning in HRD practices: an Australian study. Journal of European Industrial Training, 30(8), 608-621. doi: $10.1108 / 03090590610712278$

Campbell-Kelly, M. (1996). Information technology and organizational change in the British census, 1801-1911. Information Systems Research, 7(1), 22-36. doi: 10.1287/isre.7.1.22

Casey, A. J., \& Oliveira, F. (2011). Reflections on organizational memory and forgetting. Journal of Management Inquiry, 20(3), 305-310. doi: 10.1177/1056492611408264

Cook, S. D. N., \& Yanov, D. (1993). Culture and organizational learning. Journal of Management Inquiry, 2(4), 373-390. doi: 10.1177/105649269324010

Creswell, J. W. (2010). Projeto de pesquisa: métodos qualitativo, quantitativo e misto (3a ed.). Porto Alegre: Bookman.

Crossan, M. M., Lane, H. W., \& White, R. E. (1999). An organizational learning framework: from intuition to institution. The Academy of Management Review, 24(3), 522-537. doi: 10.5465/AMR.1999.2202135

Dickson, P. R. (1992). Toward a general theory of competitive rationality. Journal of Marketing, 56(1), 69-83. doi: $10.2307 / 1252133$

Easterby-Smith, M. (1997). Disciplines of organizational learning: contributions and critiques. Humans Relations, 50(9), 1085-1113. doi: 10.1023/A:1016957817718

Easterby-Smith, M., \& Lyles, M. A. (2011). In praise of organizational forgetting. Journal of Management Inquiry, 20(3), 311-316. doi: 10.1177/1056492611408508

Feldman, M. S. (2000). Organizational routines as a source of continuous change. Organization Science, 11(6), 611-629. doi: 10.1287/orsc.11.6.611.12529

Feldman, M. S., \& Pentland, B. T. (2003). Reconceptualizing organizational routines as a source of flexibility and change. Administrative Science Quarterly, 48(1), 94-118. doi: 10.2307/3556620

Fiol, C., \& Lyles, M. (1985). Organizational learning. Academy of Management Review, 10(4), 803813.

Giddens, A. (1984). The constitution of society. Berkeley, CA: University of California Press.

Hackman, J. R., \& Wageman, R. (1995). Total quality management: empirical, conceptual, and practical issues. Administrative Science Quarterly, 40(2), 309-343. doi: 10.2307/2393640

Hargadon, A., \& Sutton, R. I. (1997). Technology brokering and innovation in a product development firm. Administrative Science Quarterly, 42(4), 716-749. doi: 10.2307/2393655

Hedberg, B. (1981). How organizations learn and unlearn. In P. C. Nystrom \& W. H. Starbuck (Eds.), Handbook of organizational design (Vol. 1, pp. 3-27). Oxford: Oxford University Press.

Hendry, C. (1996). Understanding and creating whole organizational change through learning theory. Human Relations, 49(5), 621-641. doi: 10.1177/001872679604900505 
Huber, G. (1991). Organizational learning: the contributing processes and the literatures. Organization Science, 2(1), 88-115.

Knight, L. (2002). Network learning: exploring learning by interorganizational networks. Human Relations, 55(4), 427-454. doi: 10.1177/0018726702554003

Levitt, R. E., Thomson, J., Christiansen, T. R., Kunz, J. C., Jin, Y., \& Nass, C. (1999). Simulating project work processes and organizations: toward a micro-contingency theory of organizational design. Management Science, 45(11), 1479-1495. doi: 10.1287/mnsc.45.11.1479

Lima, S. M. V., \& Bressan, C. L. (2003). Mudança organizacional: uma introdução. In S. M. V. Lima (Ed.), Mudança organizacional: teoria e gestão (pp. 17-63). Rio de Janeiro: Editora FGV.

Malhotra, N. K. (2001). Pesquisa de marketing: uma orientação aplicada (3a ed.). Porto Alegre: Bookman.

March, J. G. (1991). Exploration and exploitation in organizational learning. Organization Science, 2(1), 71-87. doi: $10.1287 /$ orsc.2.1.71

Martin de Holan, P. (2011). Agency in voluntary organizational forgetting. Journal of Management Inquiry, 20(3), 317-322. doi: 10.1177/1056492611408265

Martin de Holan, P., \& Phillips, N. (2004). Remembrance of things past? The dynamics of organizational forgetting. Management Science, 50(11), 1603-1613. doi: $10.1287 / \mathrm{mnsc} .1040 .0273$

Nadler, D. A., Shaw, R. B., \& Walton, A. E. (1995). Discontinuous change: leading organisational transformation. San Francisco, CA: Jossey-Bass.

Nelson, R. R., \& Winter, S. G. (1982). An evolutionary theory of economic change. Cambridge, MA: Harvard University Press.

Oliveira, F. (2000). Memory systems in organizations: an empirical investigation of mechanisms for knowledge collection, storage and access. Journal of Management Studies, 37(6), 811-832. doi: $10.1111 / 1467-6486.00205$

Olivera, F., \& Argote, L. (1999). Organizational learning and core processes in new product development. In L. L. Thompson, J. Levine, \& D. Messick (Eds.), Shared cognition in organizations: the management of knowledge (pp. 297-326). Mahwah, NJ: Laurence Erlbaum Associates.

Sackman, S. A. (1992). Culture and subcultures: an analysis of organizational knowledge. Administrative Science Quarterly, 37(1), 140-161. doi: 10.2307/2393536

Spink, P. K. (2003). Pesquisa de campo em psicologia social: uma perspectiva pós-construcionista. Psicologia \& Sociedade, 15(2), 18-42. doi: 10.1590/S0102-71822003000200003

Srithika, T. M., \& Bhattacharyya, S. (2009). Facilitating organizational unlearning using appreciative inquiry as an intervention. Vikalpa: The Journal for Decision Makers, 34(4), 67-77.

Stene, E. O. (1940). An approach to the science of administration. American Political Science Review, 34(6), 1124-1137. doi: 10.2307/1948193

Tranfield, D., \& Smith, S. S. (1998). The strategic regeneration of manufacturing by changing routines. International Journal of Operations and Production Management, 18(2), 114-129. doi: $10.1108 / 01443579810193267$

Triviños, A. N. S. (1987). Introdução à pesquisa em ciências sociais: a pesquisa qualitativa em educação. São Paulo: Atlas. 
Tsang, E. W. K. (2008). Transferring knowledge to acquisition joint ventures: an organizational unlearning perspective. Management Learning, 39(1), 5-20. doi: 10.1177/1350507607085169

Tsang, E. W. K., \& Zahra, S. (2008). Organizational unlearning. Human Relations, 61(10), 1435-1462. doi: $10.1177 / 0018726708095710$

Tushman, M. L., \& Anderson, P. (1986). Technological discontinuities and organizational environments. Administrative Science Quarterly, 31(3), 439-465. doi: 10.2307/2392832

Walsh, J. P., \& Ungson, G. R. (1991). Organizational memory. The Academy of Management Review, 16(1), 57-91. doi: 10.5465/AMR.1991.4278992

Watson, G. (1969). Resistance to change. In W. G. Bennis, K. D. Benne, \& R. Chin (Eds.), The planning of change (pp. 488-498). New York: Holt, Rinehart and Winston.

Wilson, J. M., Goodman, P. S., \& Cronin, M. A. (2007). Group learning. Academy of Management Review, 32(4), 1041-1069.

Wong, P. S. P., Cheung, S. O., Yiu, R. L. Y., \& Hardie, M. (2012). The unlearning dimension of organizational learning in construction projects. International Journal of Project Management, 30(1), 94-104. doi: 10.1016/j.jproman.2011.04.001

Yin, R. K. (2010). Estudo de caso: planejamento e métodos. Porto Alegre: Bookmann.

\section{Dados dos Autores}

Gustavo Tomaz Buchele

Campus Reitor João David Ferreira Lima, 88040-900, Florianópolis, SC, Brasil. E-mail: gustavotb.adm@ gmail.com

Pierry Teza

Campus Reitor João David Ferreira Lima, 88040-900, Florianópolis, SC, Brasil. E-mail: pierryteza@ gmail.com

Isabela Regina Fornari Müller

Campus Reitor João David Ferreira Lima, 88040-900, Florianópolis, SC, Brasil. E-mail: isabela.esag@ gmail.com

João Artur de Souza

Campus Reitor João David Ferreira Lima, 88040-900, Florianópolis, SC, Brasil. E-mail: jartur@ gmail.com 